\title{
Mode II surface crack growth under rolling contact fatigue and cyclic shear stress in $\mathrm{Si}_{3} \mathbf{N}_{4}$
}

\author{
K. Kida, T. Honda \& E. C. Santos \\ Department of Mechanical Engineering, Kyushu University, Japan
}

\begin{abstract}
The effects of friction on surface crack growth behavior from pre-indentations of $\mathrm{HIP}-\mathrm{Si}_{3} \mathrm{~N}_{4}$ were investigated under rolling contact fatigue (RCF). Near surface contact stress distributions were calculated by Hanson's analytical method, and the crack growth behavior was discussed in terms of stress intensity factors under rolling contact fatigue. It was found that friction promoted surface crack growth and the cracks grew in mode II by shear stress $\left(\Delta K_{\mathrm{II}} \fallingdotseq 3.6 \mathrm{MPam}^{1 / 2}\right.$, $K_{\text {II } \max } \fallingdotseq 1.8 \mathrm{MPam}^{1 / 2}$, stress ratio $\left.R=-1\right)$. In order to confirm the effects of shear stress on surface crack growth, crack propagation tests under cyclic shear stress were carried out. We found the features concerning Mode II crack growth: 1) The cracks grew by cyclic shear stress in Mode II (initial value of $\Delta K_{\mathrm{II}}$ is 3.0 $\mathrm{MPam}^{1 / 2}$ ); 2) Under the same $\Delta K_{\mathrm{II}}=3.0 \mathrm{MPam}^{1 / 2}$, the cracks grow more when $K_{\text {II max }}=3.0 \mathrm{MPam}^{1 / 2}(R=0)$ than when $K_{\text {II max }}=1.5(R=-1)$. Comparing the features of mode II crack growth obtained from the crack propagation tests under cyclic shear stress and the RCF cracks, we conclude that the increase in values of stress intensity factors of mode II explains that the cracks under frictional contact are promoted by friction.

Keywords: rolling contact fatigue, contact stresses, shear stress, surface crack growth, mode II crack growth, $\mathrm{Si}_{3} \mathrm{~N}_{4}$.
\end{abstract}

\section{Introduction}

In the present work surface crack growth in mode II of silicon nitride is investigated based on the features of crack growth under cyclic shear stress.

Failures of bearings have been approached from the viewpoint of subsurface crack initiation [1]. However, it has also been reported that surface cracks cause 
the fatigue failures of bearings $[2,3]$. Dents are formed in bearings on the contact surface by the invasion of particles under high Hertzian pressure, so that small cracks are initiated around the surface defects. Although surface cracks cause flaking failure, surface failures are also affected by wear. Fan et al. [4] investigated the effects of friction on both wear and surface cracks when two steel disks with different hardnesses were subjected to rolling contact fatigue. In the experimental study crack growth behavior was compared with wear recession under various load conditions, and it was found that the crack initiation and propagation were controlled by both the load and steel hardness. Ceramic materials are harder than steel, which means that surfaces of ceramic materials are prevented from wearing down even if the surfaces are affected by friction. It is important to study the effects of friction on surface crack growth.

Since Zaretsky and Anderson [5] studied the application of $\mathrm{Al}_{2} \mathrm{O}_{3}$ ceramic materials to bearings, ceramic bearings have been developed because of their superior properties such as high hardness, high stiffness and lower density (Kitamura [6]). The performance of all-ceramic bearings and hybrid ceramic/steel bearings has been compared with steel bearings [7, 8]. There are many other research works investigating silicon nitride bearings (see the review by Wang et al. [9] and also Kitamura [6]). The failures caused by surface cracks of silicon nitride balls under rolling contact have been investigated based on knowledge of 'ring crack initiation [10-16]. Surface cracks of silicon nitride plates, which are used in thrust bearings, have been approached using fracture mechanics [17-20]. In these investigations, the relations between surface crack growth, contact stresses and fluid pressure have been studied. However, each relation has been investigated independently. In our previous work the effects of contact stresses on surface crack growth were investigated [18]. We concluded that the cracks are propagated by the single effect of contact stresses. In the present work in order to investigate surface cracks under rolling contact fatigue in detail from the viewpoint of shear stress, we focused on the growth of the cracks which were located near the border of the contact area and studied the effect of friction on crack growth. Furthermore we compared torsion fatigue [21] and rolling contact fatigue. Based on these observations we discuss mode II growth of surface cracks under rolling contact fatigue.

\section{Experimental procedure}

The material of the specimens was HIP-Si $\mathrm{N}_{4}$ (Toshiba, TSN-03) which is used in ceramic bearings. Table 1 presents its mechanical properties. The surfaces of the specimens were polished to the longitudinal $R a$ roughness of $0.10 \mu \mathrm{m}$. The value of fracture toughness $\left(K_{\mathrm{IC}}\right)$ was measured by IF method.

The contact fatigue tests were carried out by using a reciprocating rolling contact fatigue (RCF) machine. A plate specimen and two balls were used in this machine [19]. The machine consists of three parts: one is a hydraulic servosystem to generate relative displacement between balls and a plate; another is the ball holding apparatus that was attached to the upper chuck of the 
Table 1: $\quad$ Mechanical properties of the specimen.

\begin{tabular}{c|c|c|c|c}
\hline $\begin{array}{c}\text { Bulk } \\
\text { density } \\
\left(\mathrm{g} / \mathrm{cm}^{3}\right)\end{array}$ & $\begin{array}{c}\text { Bending } \\
\text { strength } \\
(\mathrm{MPa})\end{array}$ & $\begin{array}{c}\text { Fracture } \\
\text { toughness } \\
K_{\mathrm{IC}}\left(\mathrm{MPam}^{1 / 2}\right)\end{array}$ & $\begin{array}{c}\text { Young's } \\
\text { modulus } \\
E(\mathrm{GPa})\end{array}$ & $\begin{array}{c}\text { Poisson's } \\
\text { ratio }\end{array}$ \\
\hline 3.23 & 1011 & 6.6 & 294 & 0.27 \\
\hline
\end{tabular}

hydraulic servosystem; and the other is the plate-holder mounted on the lower chuck. Fig. 1 is the schematic illustration of the RCF test. The plate was reciprocated by a hydraulic servosystem. RCF tests were carried out under both rolling contact and frictional contact. The furrow-type ball holder was chucked by two leaf springs (see (1) in Fig. 1(a)). Strain gauges were attached to the leaf springs, and the friction forces between the ball and the plate were measured by the strain gauges (see (2)). Vertical load to the specimen surface was applied by bending the leaf spring (see (3) and (4)). The vertical load was measured in the same way as the friction forces. A box-type ball holder was used when frictional contact was tested. The lubricant was dropped to the contact area from a tube in which the lubricant flow was controlled (see (5)). The lubricant was turbine oil (ISO VG46), the viscosity of which was $43.3 \times 10^{-6} \mathrm{~m}^{2} / \mathrm{s}$ at $40^{\circ} \mathrm{C}$. The lubricant flow was about $1 \mathrm{cc} / \mathrm{min}$. When we carried out RCF tests we initiated artificial cracks (Palmqvist cracks) at the border of the contact track under a load of 19.6 N. Four Palmqvist cracks are initiated at each corner of a Vicker's indentation, and in the present work the cracks which grew in a direction perpendicular to the ball movement were observed. This is because we discuss mode II growth of surface cracks which grew under rolling contact fatigue. The ball diameter was $9.525 \mathrm{~mm}\left(3 / 8^{\prime \prime}\right)$ and the dimensions of the plate specimens were $10 \times 15 \times 4 \mathrm{~mm}$. The RCF conditions are shown in Table 2 .

Table 2: $\quad$ Experimental conditions of rolling contact fatigue tests.

\begin{tabular}{c|c|c|c|c}
\hline $\begin{array}{c}\text { Load } \\
(\mathrm{N})\end{array}$ & $\begin{array}{c}\text { Hertzian maximum } \\
\text { stress }(\mathrm{MPa})\end{array}$ & $\begin{array}{c}\text { Half width of contact } \\
\text { area, } \mathrm{c}(\mu \mathrm{m})\end{array}$ & $\begin{array}{c}\text { Frequency } \\
(\mathrm{Hz})\end{array}$ & $\begin{array}{c}\text { Stroke } \\
(\mathrm{mm})\end{array}$ \\
\hline 294 & 3979 & 188 & 2.0 & 1.5 \\
\hline
\end{tabular}

Torsion fatigue tests were conducted by a torsion-bending machine (Shimazu, TB-10B). Fig. 2 is the schematic illustration of the torsion fatigue test. The experimental conditions are shown in Table 3. When we conducted torsion fatigue tests we initiated artificial cracks (radial cracks) by Vicker's indentations at the center of the sides of bar specimens (see Fig. 2) under a load of $98 \mathrm{~N}$. The dimensions of the bar specimens were $6.8 \times 6.8 \times 78.0 \mathrm{~mm}[21]$.

The average value of the aspect ratio of the Palmqvist cracks was observed to be 0.6 in our previous work [22] and that of radial cracks was 0.9 [18]. In the following section the values of stresses and stress intensity factors are calculated based on these aspect ratios. 
(a)

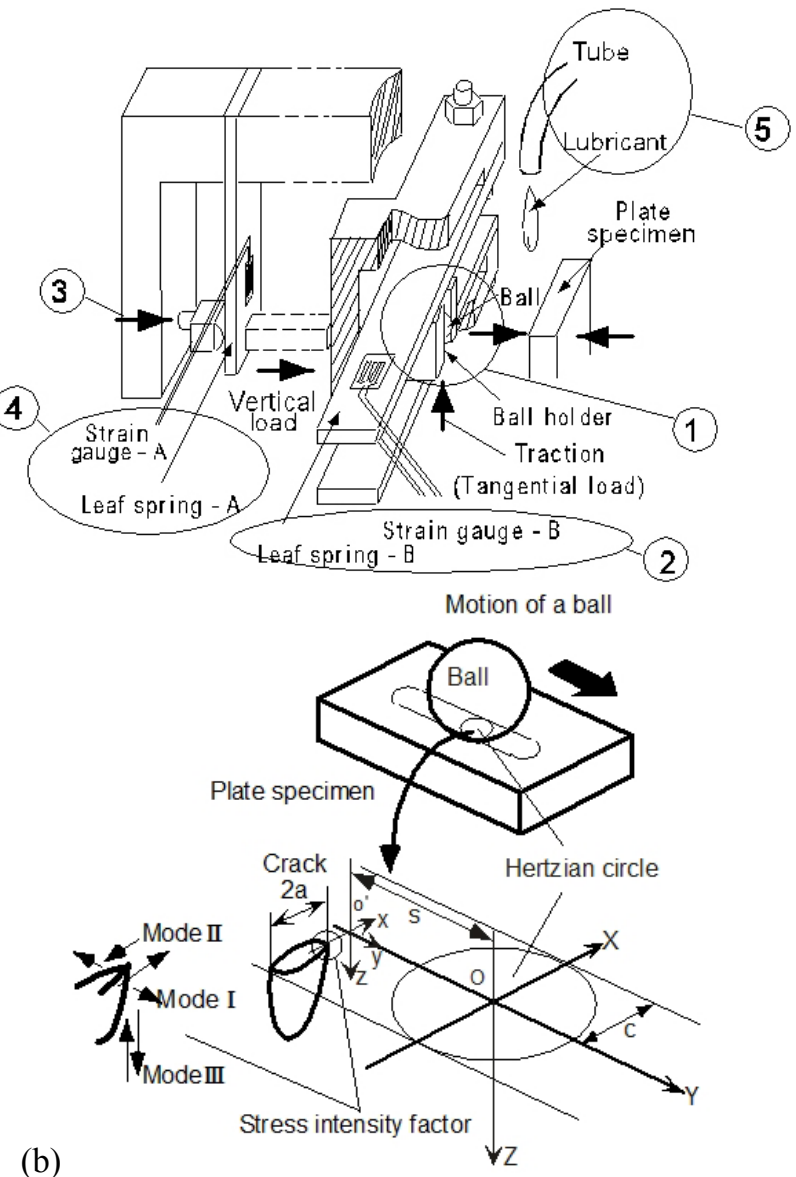

Figure 1: Schematic illustration of reciprocating-RCF (rolling contact fatigue) machine. (a) Configuration; (b) Coordinate of cracks under spherical Hertzian contact.

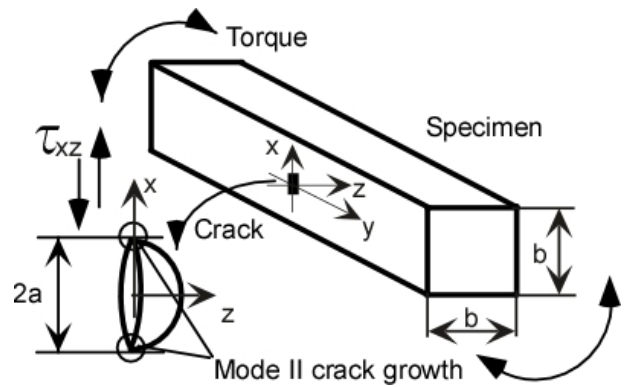

Figure 2: $\quad$ Schematic illustration of the torsion fatigue test. 
Table 3: $\quad$ Experimental conditions of torsion fatigue tests.

\begin{tabular}{c|c|c|c|c|c}
\hline Stress ratio & $\begin{array}{c}\text { Range in } \\
\text { torque } \\
(\mathrm{Nm})\end{array}$ & $\begin{array}{c}\text { Range of } \\
\text { shear stress* } \\
(\mathrm{MPa})\end{array}$ & $\begin{array}{c}\text { Maximum } \\
\text { shear stress* } \\
(\mathrm{MPa})\end{array}$ & $\begin{array}{c}\text { Minimum } \\
\text { shear stress* } \\
(\mathrm{MPa})\end{array}$ & $\begin{array}{c}\text { Cyclic } \\
\text { frequency } \\
(\mathrm{Hz})\end{array}$ \\
\hline$-1[21]$ & 4.9 & 136 & 68 & -68 & 33 \\
\hline 0 & 4.90 & 136 & 136 & 0 & \\
\hline
\end{tabular}

*These are the values of the stresses at the center of the surface of the specimen sides.

\section{Experimental results and discussion}

In this section, crack growth behavior is looked at from the viewpoints of contact stresses and stress intensity factors (SIF). First, the growth mechanisms of the cracks under rolling contact fatigue are investigated. Second, the cracks which grew under torsion fatigue tests are studied. Finally, both crack growths are compared.

\subsection{Crack growth under rolling contact fatigue}

Fig. 3 shows the crack growth behavior under cyclic rolling and frictional contacts (sliding-including-rolling contact). The friction coefficient under rolling contact was less than 0.01 and that under frictional contact was 0.1 . The crack growth direction of both cracks was not observed to change. It is interesting to note that both cracks grew slowly under rolling and frictional contacts. The cracks under frictional contact grew more than those under rolling contact. This result indicates that the friction promotes crack growth under frictional contact.

Contact stresses were calculated by the theoretical equations that Hanson [23] developed to investigate stress distributions under spherical Hertzian contact.

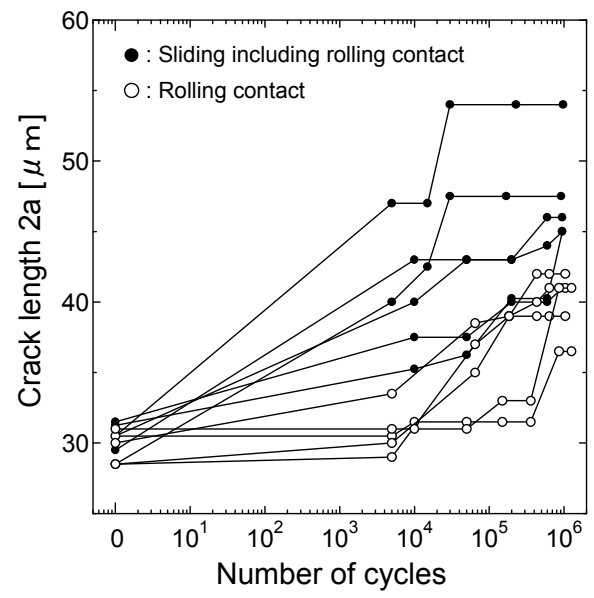

Figure 3: Crack growth behavior under rolling and frictional contacts. 
Fig. 1(b) shows the schematic illustration of the coordinate systems of the Hertzian circle and a surface. The fixed rectangular coordinate system of $X, Y$ and $Z$ is defined so that the center $O$ of the coordinate system corresponds to the contact center. The local coordinate system of $\mathrm{x}, \mathrm{y}$ and $\mathrm{z}$ is defined on the crack face. $Y$ and $y$ axes are parallel to the motion of the ball. ' $\mathrm{S}$ ' shows the relative displacement of $O$ from o' and the ball movement is shown as the change of $\mathrm{S}$.

In this paper the SIFs were calculated by using Kassir-Sih's equations [24], and the crack is assumed to be an elliptical crack located in an infinite body taking the aspect ratios of cracks into consideration. The SIFs at the surface tip of the crack were calculated in three steps: 1) The area of the semi-circular crack was divided into unit areas $\left(1 \mu \mathrm{m}^{2}\right)$. The tensile stress $\sigma \mathrm{xx}$ and the shear stresses $\tau x y, \tau x z$ on each area were calculated by using Hanson's equations; 2) The average values of the stresses on the areas covering the surface crack face were calculated; 3) The SIFs, $K_{\mathrm{I}}, K_{\mathrm{II}}$ and $K_{\mathrm{III}}$ for the stresses $\sigma \mathrm{xx}$, $\tau \mathrm{xy}$ and $\tau \mathrm{xz}$ were calculated by using Kassir-Sih's equations, respectively.

In this process the effect of the free surface and also the effect of crack face friction were ignored; however, the values calculated by the present method are increased by $17.5 \%$ in order to correlate the value to case of surface crack. The effects of the free surface on stress intensity factors of surface crack were investigated by Murakami [25]. According to Murakami's theoretical results, the stress intensity factors for a semi-circular crack in a semi-infinite body under uniform tensile stress $\sigma$ was $0.748 \sigma \sqrt{ } \pi$ a. In the calculation, the Poisson's ratio is 0.3 . This value is larger than that for a penny-shaped crack in an infinite body by $17.5 \%(=(0.748 \sigma \sqrt{ } \pi \mathrm{a}) /((2 / \pi) \sigma \sqrt{ } \pi \mathrm{a}))$. This indicates that the accurate values of stress intensity factors for a surface crack under RCF are larger than the value calculated by the present method. The effects of both free surface and threedimensional stress distribution on the values of stress intensity factors $K_{\mathrm{I}}, K_{\mathrm{II}}$ and $K_{\text {III }}$ were also investigated [26]. Tanabe et al. reported that the values calculated by the present method were predicted to be smaller than the values of results obtained from the FEM analysis. The authors think that we need to investigate the method for calculating accurate values of stress intensity factors of surface cracks under RCF. However, before investigating the method in detail it is important to check what is the dominant factor for understanding the crack growth under RCF.

Friction coefficient of frictional contact (sliding-including-rolling contact) $=$ 0.1 . ' $2 a$ ' is crack length.

Fig. 4 shows the changes of SIFs for both cracks under rolling contact and frictional contact while a ball moves forward and backward. In Fig. 4 the surface length of the crack is $30 \mu \mathrm{m}$. Comparing the peak values of rolling and frictional contacts, we noticed the following features of stress intensity factors.

1) Stress intensity factors under frictional contact are larger than those under rolling contact.

2) Absolute values under frictional contact of both maximum and minimum $K_{\text {II }}$ while a ball moves forward and backward are larger than those under rolling contact. 


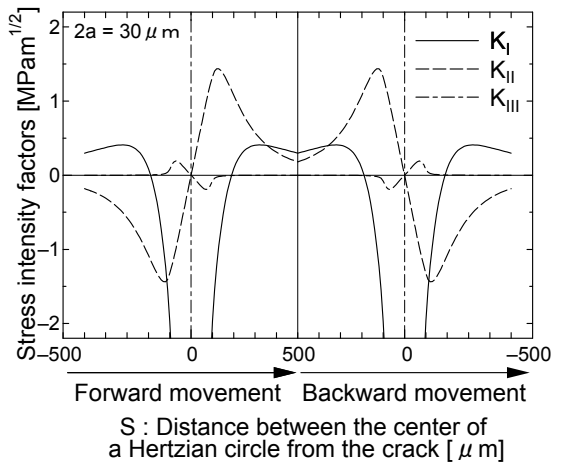

(a) Rolling contact.

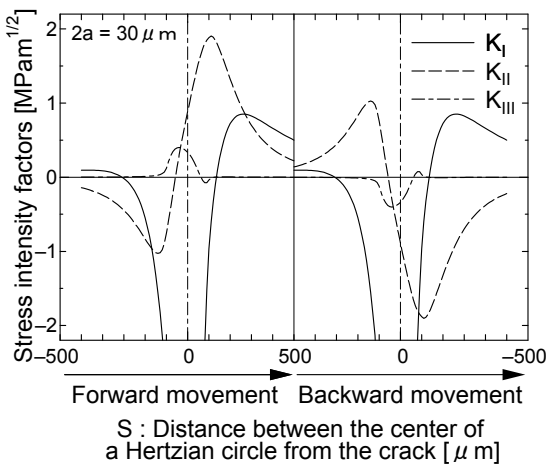

(b) Frictional contact.

Figure 4: Variations of the stress intensity factors for the perpendicular crack during a ball reciprocating cycle. ' $a$ ' is crack length.

Fig. 5 illustrates the changes of $K_{\mathrm{I}}, K_{\mathrm{II}}$ and $K_{\mathrm{III}}$ as cracks grow under both rolling and frictional contacts. The data for the cracks, the surface lengths of which are $30 \mu \mathrm{m}$ and $50 \mu \mathrm{m}$, are plotted during a half cycle. Under rolling contact, the comparison of both cracks $\left(30 \mu \mathrm{m}\right.$ and $50 \mu \mathrm{m}$ in Fig. 5(a)) shows that $K_{\operatorname{Imax}}$ and the values of $K_{\mathrm{II}}$ and $K_{\mathrm{III}}$ increase when cracks grow. The features of $K_{\mathrm{I}}, K_{\mathrm{II}}$ and $K_{\mathrm{III}}$ under frictional contact are nearly the same as those under rolling contact as shown in Fig. 5(b). It is noted that $K_{\text {Imax }}$ is exerted on the crack mouth twice during a half cycle under rolling contact, but under frictional contact $K_{\text {Imax }}$ is applied to the crack only once after a ball passes the crack. The features of the $50 \mu \mathrm{m}$ crack are exactly the same as those of the $30 \mu \mathrm{m}$ crack, which indicates that the crack growth mode does not change while cracks grow.

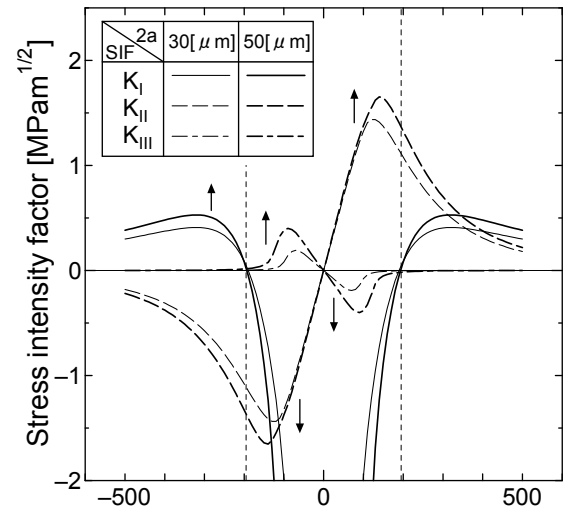

$\mathrm{S}:$ Distance from center of Hertzian circle to crack [ $\mu \mathrm{m}]$

(a) Rolling contact.

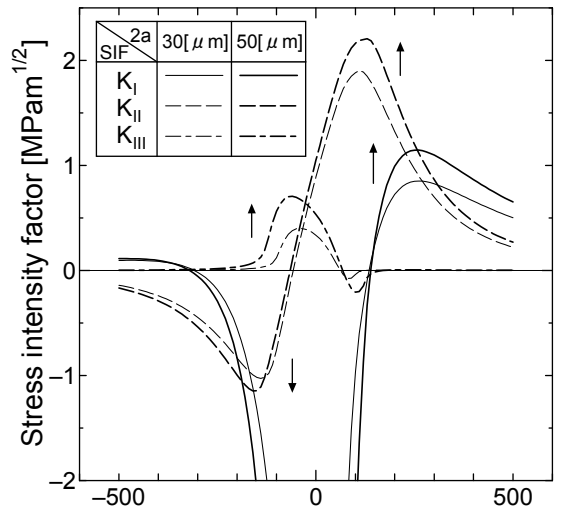

$S$ : Distance from center of Hertzian circle to crack [ $\mu \mathrm{m}]$

(b) Frictional contact.

Figure 5: Examples of the change in the stress intensity factors with crack length. 
Fig. 6 shows the changes of $K_{\text {Imax }}, \Delta K_{\text {II }}$ and $\Delta K_{\text {III }}$ as cracks grow. The SIFs were calculated for crack lengths ranging from $24 \mu \mathrm{m}$ to $80 \mu \mathrm{m}$ and these are drawn as curves in Fig. 6 . The mean values of $K_{\text {Imax }}, \Delta K_{\mathrm{II}}$ and $\Delta K_{\mathrm{III}}$ are also plotted in the ranges from $10^{(\mathrm{n}-1)}$ to $10^{\mathrm{n}}$ cycles for each mean crack length measured in the experiments. $\Delta K_{\mathrm{II}}$ and $\Delta K_{\mathrm{III}}$ are calculated as $\left|K_{\max }-K_{\min }\right|$ for a reciprocating cycle.

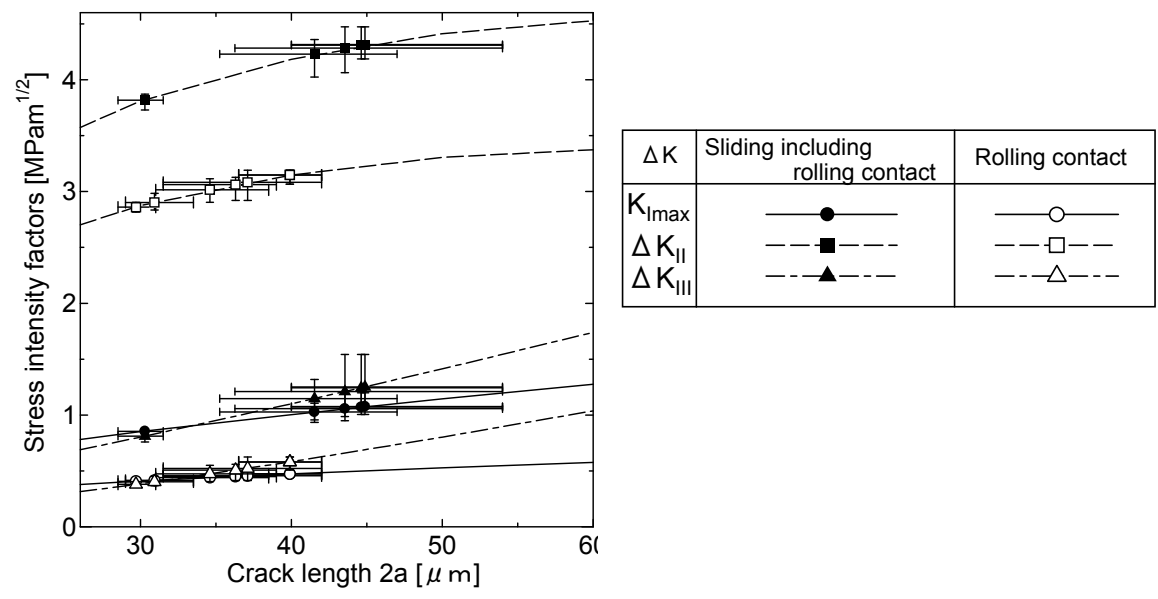

Figure 6: Stress intensity factor ranges as a function of crack length.

$\Delta K_{\mathrm{II}}$ is larger than $K_{\mathrm{Imax}}$ and $\Delta K_{\mathrm{III}}$ under both rolling and frictional contacts, so it is found that the $\Delta K_{\text {II }}$ dominantly affects the crack growth. All values of $K_{\text {Imax }}$, $\Delta K_{\mathrm{II}}$ and $\Delta K_{\mathrm{III}}$ under frictional contact are found to be larger than those under rolling contact, so that the friction increases the values of $K_{\text {Imax }}, \Delta K_{\mathrm{II}}$ and $\Delta K_{\mathrm{III}}$. We can understand the experimental results about crack growth from these features as follows: the cracks under frictional contact grow more than those under rolling contact because the friction force increases the values of stress intensity factors. We therefore concluded that friction promoted surface crack growth.

When comparing the values of stress intensity factor range $\Delta K_{\mathrm{II}}$ under frictional and rolling contacts, we notice that the value of $\Delta K_{\mathrm{II}}$ under frictional contact is larger than that under rolling contact. This feature of $\Delta K_{\mathrm{II}}$ is also applicable to the absolute values of $K_{\text {IImax }}$ and $K_{\text {IImin }}$. However, the number of cycles of $\Delta K_{\mathrm{II}}, K_{\mathrm{IImax}}$ and $K_{\mathrm{IImin}}$ under frictional contact while a ball reciprocates is half that under rolling contact. This indicates that the increase in absolute values of $K_{\text {IImax }}$ and $K_{\text {IImin }}$ under frictional contact is more important to evaluate crack growth than the decrease of the number of cycles. Here two questions arise: 'Is this true or not?' and 'Are there other factors affecting crack growth under rolling contact fatigue?' Furthermore the values of $\Delta K_{\mathrm{II}}, K_{\mathrm{IImax}}$ and $K_{\mathrm{IImin}}$ increase under frictional contact and also they are larger than any other stress intensity factors. However, not only $\Delta K_{\text {II }}, K_{\text {IImax }}$ and $K_{\text {IImin }}$ but also the values of $K_{\text {Imax }}$ 
increase under frictional contact. In this case another question arises: 'Does the increase in values of stress intensity factors of mode II alone explain that the cracks under frictional contact are promoted by friction?'

The results obtained from the stress intensity factors calculated in the present work explain the features of crack growth well under rolling contact fatigue, but the questions which were mentioned above remain. In the present work, in order to answer the questions, simple tests concerning crack growth under cyclic shear stress were conducted. From Fig. 6 the minimum values of $\Delta K_{\text {II }}$ under rolling contact and frictional contact were found to be about 2.8 and $3.6 \mathrm{MPam}^{1 / 2}$, respectively. We carried out torsion fatigue tests under the conditions in which $\Delta K_{\text {II }}$ is less than $3.8 \mathrm{MPam}^{1 / 2}$ and investigated the effects of shear stress on crack growth. When carrying out the torsion fatigue tests, we used the larger-sized initial crack, whose surface length was $300-400 \mu \mathrm{m}$; this is larger than that used in RCF tests. This is because when we conducted torsion fatigue tests using the pre-cracked bar specimens, whose surface length was the same as the RCF cracks, the failures were caused by defects inside the specimens, so that it was difficult to observe the crack growth.

\subsection{Torsion fatigue test}

Table 3 shows the experimental conditions of the torsion fatigue tests. Under condition of stress ratio $(R)=-1$, initial value of average $\Delta K_{\text {II }}$ was about 3.0 $\mathrm{MPam}^{1 / 2}, K_{\text {IImax }}$ was about $1.5 \mathrm{MPam}^{1 / 2}$ and $K_{\text {IImin }}$ was about $-1.5 \mathrm{MPam}^{1 / 2}$. In order to investigate the effects of stress ratio on crack growth, the tests were also carried out under conditions of $R=0$. Under the condition of $R=0, \Delta K_{\mathrm{II}}\left(\fallingdotseq 3.0 \mathrm{MPam}^{1 / 2}\right)$ is the same as in $R=-1$, but the stress ratio $R$ was 0 $\left(K_{\text {IImax }} \fallingdotseq 3.0 \mathrm{MPam}^{1 / 2}\right.$ and $\left.K_{\text {IImin }}=0.0 \mathrm{MPam}^{1 / 2}\right)$. Figs. 7 (a) and (b) show the crack growth behavior under stress ratio $R=-1$ and 0 , respectively. The solid marks $\bullet$ in Fig. 7 are the data for the crack which caused the failure during the tests. The crack in Fig. 7(a) grew to $520 \mu \mathrm{m}$ and changed the growth direction at the number of cycles $\mathrm{N} \fallingdotseq 4.5 \times 10^{5}$ from a direction parallel to the maximum shear stress to a direction perpendicular to the maximum tensile stress. After the crack changed growth direction it caused the failure when the number of cycles was $\mathrm{N} \fallingdotseq 8.1 \times 10^{5}$. The final growth direction of the crack was observed to be perpendicular to the tensile stress. This indicates that after the crack grew in mode II, it was propagated in mode I and caused a failure in the present experiments. On the other hand, other cracks grew in a direction parallel to the maximum shear stress but these did not result in any failures by the time we stopped the observations at $\mathrm{N} \fallingdotseq 8.1 \times 10^{5}$ cycles.

Here the stress values shown in both Table 3, Figs. 7 (a) and (b) are the values of the stresses at the center of the surface of the specimen sides. Shear stress on the unit area $\left(1 \mu \mathrm{m}^{2}\right)$ was calculated by using equations (1)-(3) below.

$$
\tau=G \theta\left(2 x-\frac{16 b}{\pi^{2}} \sum_{n} \frac{(-1)^{\frac{n-1}{2}}}{n^{2}} \frac{\sin \alpha_{n} x \cosh \alpha_{n} y}{\cosh \alpha_{n} b}\right)
$$




$$
\begin{gathered}
\theta=\frac{T}{16 \alpha^{4} \beta G} \\
\alpha_{n}=\frac{n \pi}{2 b} \quad(n=1,3,5)
\end{gathered}
$$

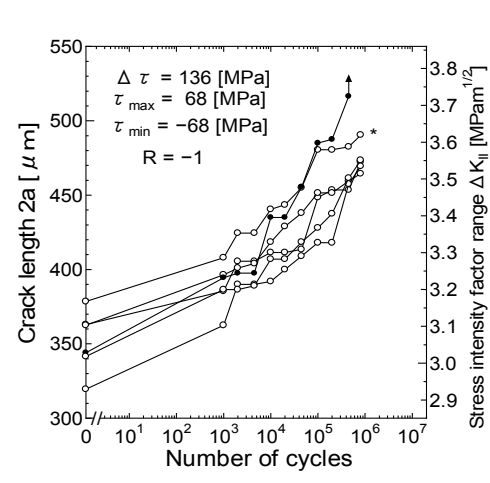

(a) Stress ratio $R=-1[21]$.

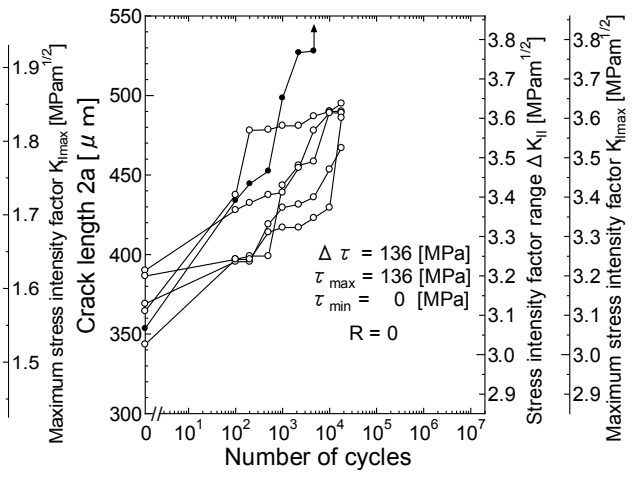

(b) Stress ratio $R=0$.

Figure 7: Crack growth behavior under cyclic torsion fatigue.

The average values of shear stresses are substituted for Kassir-Sih's equation on unit areas covering the crack face, and the stress intensity factor at the surface tip of the crack is obtained. Here, $b(=6.8 \mathrm{~mm})$ is the side length of the sectional square of the specimens. $G(=116 \mathrm{GPa})$ is shear modules, and $\beta(=0.141)$ is the constance for the shape of the section of the specimen.

Fig. 7 also shows an important feature of surface cracks in silicon nitride, i.e. the surface cracks grow slowly in mode II under the condition in which $\Delta K_{\text {II }}$ is about $3.0 \mathrm{MPam}^{1 / 2}$. The crack lengths under condition of $R=-1$ became $450 \mu \mathrm{m}$ when the number of cycles was in the range from $3.0 \times 10^{4}$ to $4.0 \times 10^{5}$ cycles, while the crack lengths under $R=0$ became the same length $(450 \mu \mathrm{m})$ as in condition of $R=-1$ when the number of cycles was in the range from $1.0 \times 10^{2}$ to $1.5 \times 10^{4}$ cycles. Comparison of the number of cycles under conditions of $R=-1$ and 0 shows that the cracks under condition of $R=0$ grew faster than those under $R=-1$. This indicates that the cracks grow faster when $R=0$ than when $R=-1$, i.e., the cracks grow more when $K_{\text {IImax }}$ becomes larger even under the conditions in which $\Delta K_{\text {II }}$ is the same value. Furthermore, we note that the range of cycles under condition $R=-1$ is more than 2.7 times the range under $R=0$, which indicates that the crack growth speed under $R=0$ is more than 2.7 times that under $R=-1$. The values of $K_{\text {IImax }}$ under condition of $R=0$ are twice as much as those under $R=-1$. When comparing the different rates of $K_{\text {IImax }}$ and crack growth speed under conditions of $R=0$ and -1 we concluded that the increase in $K_{\text {IImax }}$ promotes crack growth at a rate which is more than that of $K_{\text {IImax }}$. As mentioned in the section on rolling contact fatigue, we concluded that friction promotes crack growth. Furthermore the comparisons of the number of 
cycles and values of both $\Delta K_{\mathrm{II}}$ and $K_{\mathrm{IImax}}$ under rolling and frictional contacts implies that the increase in values of $K_{\mathrm{II}}$ is more important to evaluate crack growth than the decrease of the number of cycles under RCF.

Based on the features of mode II crack growth under cyclic shear stress we can explain the crack growth under rolling and frictional contacts as follows. The number of cycles of $K_{\text {IImax }}$ decreased by the friction while a ball reciprocates is half that under rolling contact. However the stress intensity factors of mode II are increased by friction. The stress intensity factors affect crack growth more than expected by the decrease in the number of cycles of stress intensity factors of mode II.

\section{Conclusions}

Surface crack growth behavior from pre-indentations of $\mathrm{HIP}-\mathrm{Si}_{3} \mathrm{~N}_{4}$ was observed under rolling contact fatigue (RCF), and was investigated from the viewpoint of mode II crack growth based on the results of cracks which grew under cyclic shear load. The cracks grew more under frictional contact than under rolling contact. This indicated that friction promoted surface crack growth. Near surface contact stress distributions were calculated by Hanson's analytical method, and the crack growth behavior was discussed using fracture mechanics. Furthermore, in order to investigate crack growth in detail, crack growth tests under cyclic shear stress were conducted, and we concluded that under the same $\Delta K_{\mathrm{II}}=3.0$ $\mathrm{MPam}^{1 / 2}$, the cracks grow more when $K_{\text {IImax }}=3.0 \mathrm{MPam}^{1 / 2}(R=0)$ than when $K_{\text {IImax }}=1.5 \mathrm{MPam}^{1 / 2}(R=-1)$. Comparing the features of mode II crack growth obtained from the crack propagation tests under cyclic shear stress and the RCF cracks, the increase in values of stress intensity factors of mode II alone explain that the cracks under frictional contact are promoted by friction. Therefore we conclude that the surface cracks are propagated in mode II under rolling contact fatigue.

\section{References}

[1] Ioannides, E. and Harris, T. A., A new fatigue life model for roller bearings. Trans. ASME, J. Trib., 107, pp. 367-378. 1985.

[2] Murakami, Y, Application of fracture mechanics to tribology problems. Trans. JSME, A, 59, 283-290, 1993 (in Japanese).

[3] Yamamoto, T., Fatigue life and reliability of rolling bearings. J. of Japanese Soc. of Tribologists, 42, pp. 912-917, 1997.

[4] Fan, H., Keer, L. M., Cheng, W. and Cheng, H. S., Competition Between Fatigue Crack Propagation and Wear, ASME J. Tribology, 115, pp. 141147, 1993.

[5] Zaretsky, E. V. and Anderson, W. J., Rolling-contact fatigue studies with four tool steels and crystallized glass ceramic, Trans. ASME Jour. Basic Engineering, 83, 4, pp. 603-612. 1961. 
[6] Kitamura, K., Performance and application of ceramic rolling bearings. Jour. of Japanese Soc. of Tribologists, 45, 4, pp. 298-303, 2000 (in Japanese).

[7] Miner, J. R., Dell, J., Galbato, A. T. and Ragen, M. A. F-117-PW-100 Hybrid Ball Bearing Ceramic Technology Insertion. Trans. ASME, Jour. Eng, for Gas Turb. and Power, 118, pp. 434-442, 1996.

[8] Tanimoto, K., Kajihara, K. and Yanai, K., Hybrid Ceramic Ball Bearings for Turbochargers. SAE Paper 2000-01-1339, pp. 1-14, 2000.

[9] Wang, L., Snidle, R. W. and Gu, L. Rolling contact silicon nitride bearing technology: a review of recent research. Wear, 246, pp. 159-173, 2000.

[10] Hadfield, M., Failure of silicon nitride rolling elements with ring crack defects. Ceramics. Int., 24, pp. 379-386, 1998.

[11] Hadfield, M. and Stolarski, T. A., The effect of the test machine on the failure mode in lubricated rolling contact of silicon nitride. Trib. Int., 28, pp. 377-382, 1995.

[12] Wang, Y. and Hadfield, M., The influence of ring crack location on the rolling contact fatigue failure of lubricated silicon nitride: experimental studies. Wear, 243, pp. 157-166, 2000.

[13] Wang, Y. and Hadfield, M., The influence of ring crack location on the rolling contact fatigue failure of lubricated silicon nitride: fracture mechanics analysis. Wear, 243, pp. 167-174, 2000.

[14] Wang, Y. and Hadfield, M., Ring crack propagation in silicon nitride under rolling contact. Wear, 250, pp. 282-292, 2001.

[15] Chen, Z., Cuneo, J. C., Mecholsky, J. J. Jr. and Hu, S., Damage processes in $\mathrm{Si}_{3} \mathrm{~N}_{4}$ bearing material under contact loading. Wear, 198, pp. 197-207, 1996.

[16] Wang, Y. and Hadfield, M., Rolling contact fatigue failure modes of lubricated silicon nitride in relation to ring crack defects. Wear, 225-229, pp. 1284-1292, 1999.

[17] Kida, K., Saito, M. and Kitamura, K., Flaking failure originated from a single surface crack in silicon nitride under rolling contact fatigue, Fatigue \& Fracture of Engineering Materials \& Structures, 28, pp. 1087-1097, 2005.

[18] Kida, K., Urakami, M., Yamazaki, T. and Kitamura, K., Surface crack growth of silicon nitride bearings under rolling contact fatigue, Fatigue \& Fracture of Engineering Materials \& Structures, 27, pp. 657-668, 2004.

[19] Kida, K., Flaking Failure in Silicon Nitride under Reciprocating Rolling Contact Fatigue, Advanced Materials Research, 217-218, pp. 866-873, 2011.

[20] Kida, K., Honda, T and Santos, E. C., Semi-circular Surface Cracks and Flaking Failures in Silicon Nitride Bearings, Advanced Materials Letters, 2, 4, pp. 336-34, 2011.

[21] Kida, K, Honda, T. and Santos, E. C., Surface Crack Growth from Small Indentations in a Silicon Nitride Square Bar under Cyclic Reversed Torsion, Applied Mechanics and Materials Journal, 2012, in press. 
[22] Kida, K. and Ogura, K., Observations of Surface Crack Growth and Wear in $\mathrm{Si}_{3} \mathrm{~N}_{4}$ under Ball-on-Plate Contact, Trans. A, JSME, 65, 632, pp. 846852, 1999. (In Japanese).

[23] Hanson, M. T., The elastic field for spherical Hertzian contact including sliding friction for transverse isotropy. ASME J. Trib., 114, pp. 606-611, 1992.

[24] Kassir, M. K. and Sih, G. C., Three-Dimensional Stress Distribution Around an Elliptical Crack Under Arbitrary Loadings, ASME Ser E, $J$. Appl. Mech, 33, pp. 601-611, 1996.

[25] Murakami Y, Analysis of stress intensity factors of modes I, II and III for inclined surface cracks of arbitrary shape, Eng. Frac. Mech., 22, pp. 101114, 1985.

[26] Tanabe, H., Miyoshi, Y., Takamatsu, T. and Iwatani, S., Evaluation of stress intensity factor of surface crack under ball-on-plate contact loading, Proc. JSME Kansai, pp. 6-41 - 6-42. 2003. (In Japanese). 